\title{
Two interesting Pterula species from Maharashtra, India
}

\section{Senthilarasu G}

National Facility for Culture Collection of Fungi, Mycology \& Plant Pathology Group, Agharkar Research Institute, G. G. Agarkar road, Pune-411 004, India. Email-senthilarasug@rediffmail.com, senthilarasug28@gmail.com

Senthilarasu G 2013 - Two interesting Pterula species from Maharashtra, India. Mycosphere 4(4), 766-771, Doi 10.5943/mycosphere/4/4/13

\begin{abstract}
Two interesting species of clavarioid fungi Pterula indica sp. nov. and P. verticillata collected from Pune, Maharashtra, India are described, illustrated and discussed with closely allied species. Of these, Pterula indica is a new species characterized by the reddish brown to dark brown basidiomes, branched polychotomously below, dichotomously at the apex with white to yellowish white, acute apices, and having cylindric, smooth basidiospores and hyphoid to cylindric cystidia with short mucronate apex. Pterula verticillata is distinguished by pale orange to peach basidiomes that branched polychotomously below, verticillately to irregularly above, and having cylindric, smooth basidiospores and hyphoid cystidia with rostrate apex.
\end{abstract}

Key words - Basidiomycota - clavarioid fungi - fungal diversity - macrofungi - taxonomy

\section{Introduction}

A worldwide monograph of clavarioid fungi was provided by Corner $(1950,1970)$ in which, all the recognized taxa were critically revised and classified. Later, Petersen extensively studied the type specimens and contributed significantly on the knowledge of taxonomy of clavarioid fungi occurring in different regions (1966, 1967a,b, 1968a,b, 1969, 1971a,b, 1978a,b, 1979, 1984, 1988a,b). Pegler \& Young (1985) studied the basidiospore structures in Ramariopsis and allied genera such as Clavulinopsis and Scytinopogon. Garcia-Sandoval et al. (2005), Dentinger \& Laughlin (2006) and Kautmanová et al. (2012) studied the phylogenetic analysis of clavarioid fungi. Several clavarioid fungi have been recently described from different regions (Zhang et al. 2005, Olariaga \& Salcedo 2009, Young \& Fechner 2009). Thind (1961) made a significant contribution on Indian clavarioid fungi and compiled a monograph 'The Clavariaceae of India'. The species included were largely collected from Himalayas and a few from West Bengal, India. One of the genera of clavarioid fungi, Pterula Fr. (Pterulaceae Corner) is characterized by the erect, branched to simple, filiform and minute basidiomes having dimitic hyphal system with hyaline skeletal hyphae in the context. The genus comprises of about 50 species distributed worldwide particularly in tropics (Kirk et al. 2008). However, only two species P. decumbens Corner, Thind \& Dev (Corner et al. 1957) and P. penicillata Lloyd (Thind 1961) have been described so far from India. However, Thind (1961) clearly stated that the identity of $P$. penicillata collected by P.L. Day is doubtful and no description was provided. Instead of describing the fungus, Lloyd (1919-1925) merely provided one illustration for this fungus and he thought the fungus was similar to the collection made from USA. Corner (1950) felt based on the illustration provided by Lloyd (1919-1925) that it could be P. verticillata Corner. Apparently, there are no 
other reports of this genus from India. The knowledge on diversity of clavarioid fungi from Western Ghats of southern India is scanty. A total of only 19 species viz., Clavaria zollingeri, Clavulina cristata, C. rugosa, Clavulinopsis aurantiocinnabarina, C. corniculata, $C$. dichotoma, $C$. fusiformis, C. laeticolor, C. luteoalba, Ramaria apiculata, $R$. cokeri, $R$. eumorpha, $R$. flava, $R$. Formosa, $R$. gracilis, $R$. pallid, $R$. versatilis, Ramariopsis kunzei and $R$. pulchella have been recorded from Kerala state (Mohanan 2011) and only one species Ramaria zippelii has been recorded from Western Ghats of Maharashtra (Senthilarasu 2013). Hence, a study was initiated on clavarioid fungi of Western Ghats. In the present paper, Pterula indica collected from Pune University Campus, Pune is described, illustrated and discussed with similar taxa. Pterula verticillata is being reported for the first time from Western Ghats.

\section{Methods}

Thin sections were made from dried specimens, revived in $10 \% \mathrm{KOH}$, and stained in $2 \%$ Phloxine. Approximately 50 basidiospores from sections were measured excluding the apiculus and ornamentation. The range of spore measurements with extreme values in parentheses precedes the mean spore measurement in parentheses. The colour terms and notations are from Kornerup \& Wanscher (1978). The type specimens are deposited at Ajrekar Mycological Herbarium (AMH), MACS’ Agharkar Research Institute, Pune, India.

\section{Results}

Pterula indica G. Senthilarasu sp. nov.

Figs. 1, 3B MycoBank 561873. India.

Etymology - The epithet 'indica' refers that this species is collected and described from

Differs from $P$. verticillata in having reddish brown to dark brown basidiomes with branches polychotomous below and dichotomous at the yellowish white apex and hyphoid to cylindric cystidia with mucronate apex.

Material examined - India, Maharashtra state, Pune, Pune University Campus $\left(18^{\circ} 31^{\prime} 18.4^{\prime \prime} \mathrm{N} \mathrm{73}{ }^{\circ} 49^{\prime} 53.6^{\prime \prime E}\right)$, on ground (soil), Acacia forest, 19.10.2010, Dalbergia plantations, 28.09.2011. Collected by G. Senthilarasu (Holotype AMH 9430).

Basidiomes terrestrial, 50-75 $\times 50-200 \mathrm{~mm}$, gregarious or in clumps, erect, branched polychotomously below, dichotomously at the apex, tubular. Stipe short, up to $10 \times 20 \mathrm{~mm}$, brittle; surface reddish brown (8E8) to dark brown (8F8), becoming dark, apices white to yellowish white (4A2), subulatus, acute, glabrous.

Basidiospores (4.5)5-7 × (2)3-3.5(4), (6.12 $\pm 0.53 \times 2.96 \pm 0.12) \mu \mathrm{m}, \mathrm{Q}=2.06$, cylindric, hyaline, smooth, thin-walled, 1-2 guttulate. Basidia 20-32 × 7.5-9.5 $\mu \mathrm{m}$, cylindric clavate, bisporic to tetrasporic, sterigmata up to $4 \times 1 \mu \mathrm{m}$, thin-walled, guttulate. Cystidia 18-26.5 $\times 4.5-$ $5.5 \mu \mathrm{m}$, hyphoid to cylindric with short mucronate apex, hyaline, thin-walled. Hyphal system dimitic, skeletal hyphae up to $8.5 \mu \mathrm{m}$ diam., thick-walled, subhyaline to yellowish brown, not inflated; generative hyphae $2-5 \mu \mathrm{m}$ diam., hyaline, not inflated, thin-walled with clamp connections.

Pterula indica is very striking species growing largely on soil, is easily recognized by the reddish brown to dark brown basidiomes with white to yellowish white apices. Pterula verticillata differs from $P$. indica in having pale orange to peach basidiomes that branched profusely in verticillate manner. In addition, the branches are shiny and lucidus in $P$. verticillata. Whereas, the basidiomes of $P$. indica are branched polychotomously below and dichotomously at the apex. Pterula subulata Fr. differs from $P$. indica in having subulate, white to grayish basidiomes and presence of large, ovoid spores $(8-10 \times 5-7 \mu \mathrm{m}$ vs $4.5-7 \times 2-4 \mu \mathrm{m})$. Pterula gracilis (Desm. \& Berk.) Corner (Corner 1950) has white, shiny, translucent, slightly hairy, simple and unbranched basidiomes. Whereas, $P$. indica has reddish brown to dark brown, profusely branched, dull, smooth basidiomes having white, acute apices. 


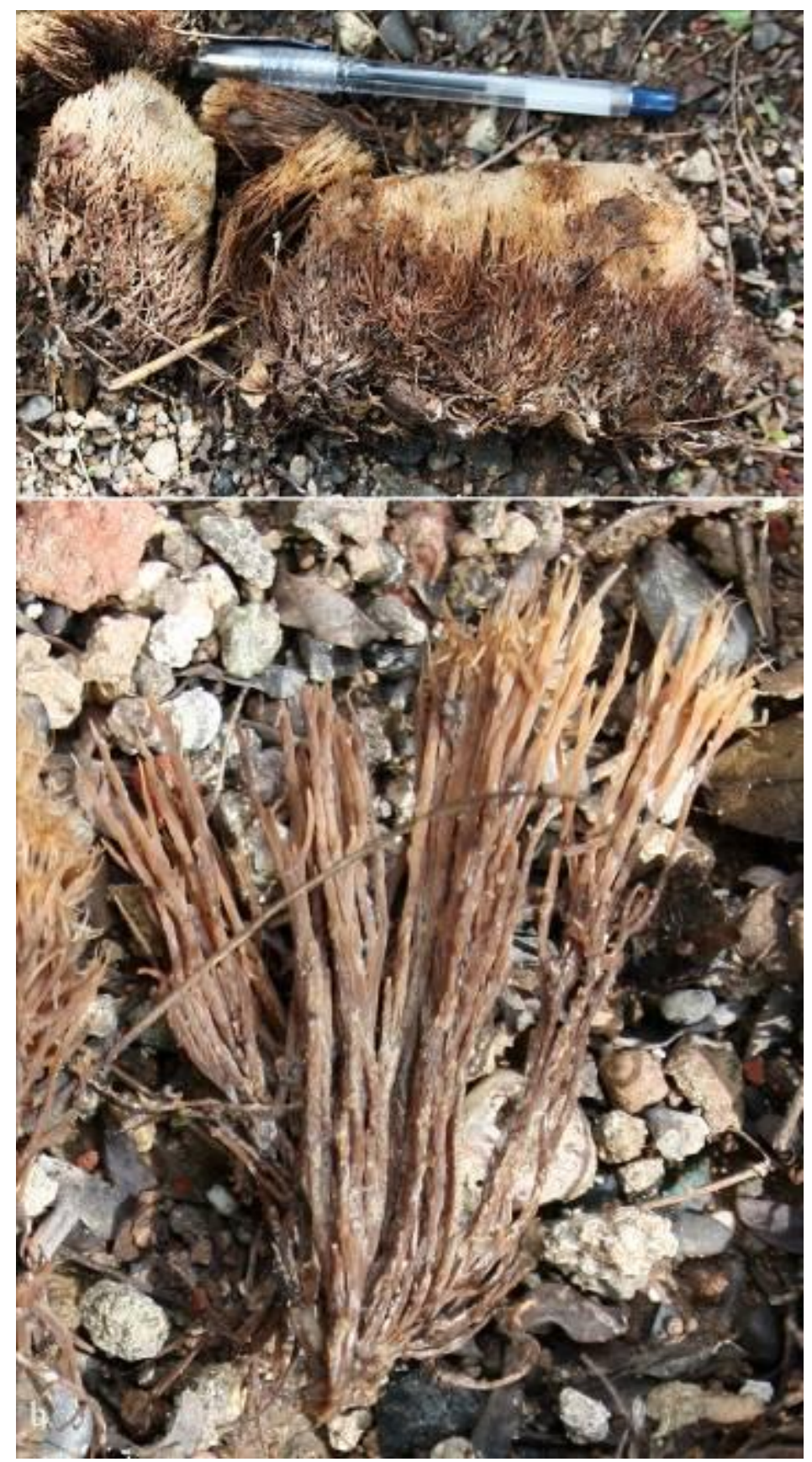

Fig. 1 - Pterula indica. Macroscopic features. a Basidiomes in situ (Holotype AMH 9430). b Individual basidiome. Photos by G. Senthilarasu.

\section{Pterula verticillata Corner}

Figs 2, 3A

Specimens Examined - INDIA, Maharashtra state, Pune, Pune University Campus $\left(18^{\circ} 31^{\prime} 18.4^{\prime \prime} \mathrm{N} 73^{\circ} 49^{\prime} 53.6^{\prime \prime} \mathrm{E}\right)$, on ground (soil), Acacia forest, 13.08. 2010, 28.09.2011. Collected by G. Senthilarasu. (AMH 9429, AMH 9458).

Basidiomes 20-40 × 20-50 mm, erect. Stipe rudimentary to well developed, 10-25 × 3-5 $\mathrm{mm}$, cylindrical, main axis arising from mycelial threads, binding the base of the basidiomes closely to the substrate, initially colourless, translucent, profusely branched, polychotomous below, verticillately to irregularly branched above, cylindric, sterile apices acute, branches initially translucent, becoming shiny in age, apices remaining translucent even in matured branchlets; surface pale orange (5A3, 6A3) to peach (7A4). Axils acute to subacute; branchlets divergent; very thin, becoming hairy on drying. 
Basidiospores (5)6-7(7.5) $\times(2.5) 3-3.5,(6.53 \pm 0.6 \times 3.15 \pm 0.23) \mu \mathrm{m}, \mathrm{Q}=2.07$, cylindric, hyaline, smooth, apiculus not prominent, guttulate, 1-2 small guttules present. Basidia 12-18 $\times 6-$ $8 \mu \mathrm{m}$, cylindrical, becoming short clavate, bisporic to tetrasporic, sterigmata short and thin, guttulate, thin-walled. Cystidia 14-60 × 5-7 $\mu \mathrm{m}$, hyphoid with long rostrate apex, hyaline, thinwalled. Hyphal system dimitic; skeletal hyphae up to $7 \mu \mathrm{m}$ diam., thick-walled, wall up to $1 \mu \mathrm{m}$ thick, brown; generative hyphae 1-4 $\mu \mathrm{m}$ diam., inflated to $10 \mu \mathrm{m}$ diam., hyaline, yellowish brown in mass, thin-walled with clamp connections.

Pterula verticillata is a very distinctive species growing largely on soil, occupies large area of soil and the mycelium also extensively colonize the litter and produce basidiomes every year during monsoon (August-October). Pterula verticillata closely resembles $P$. decumbens (Corner et al. 1957) described from India. However, $P$. decumbens clearly differs from $P$. verticillata by its decumbent, brown basidiomes, and composed of main axis which gives off lateral branches, attached to the substratum by numerous rhizoidal branches. Whereas $P$. verticillata has erect, pale orange to peach basidiomata and the main axis gives off verticillate to irregular branches.

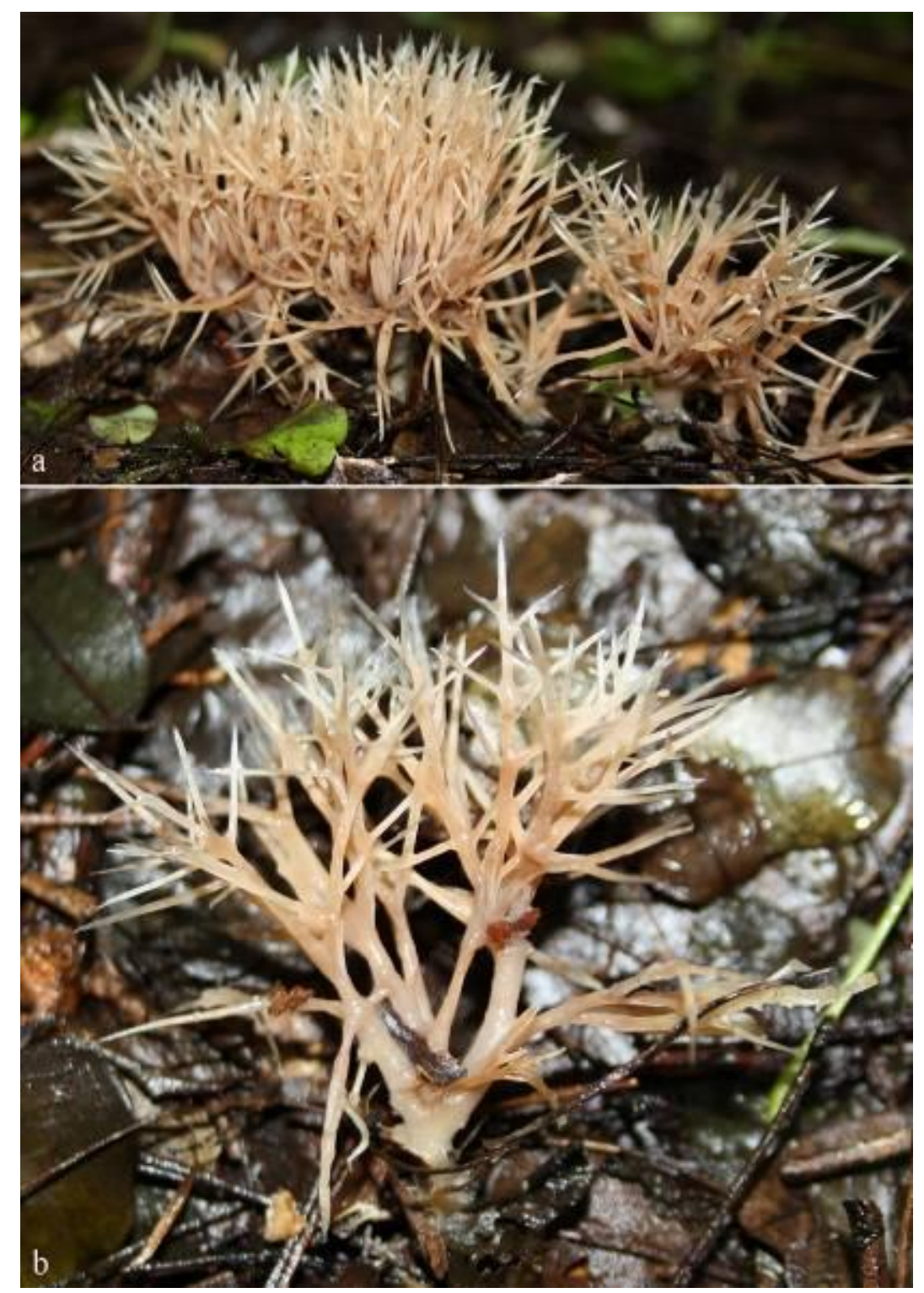

Fig. 2 - Pterula verticillata. Macroscopic features. a. Basidiomes in situ. b. Individual basidiome. Photos by G. Senthilarasu. 

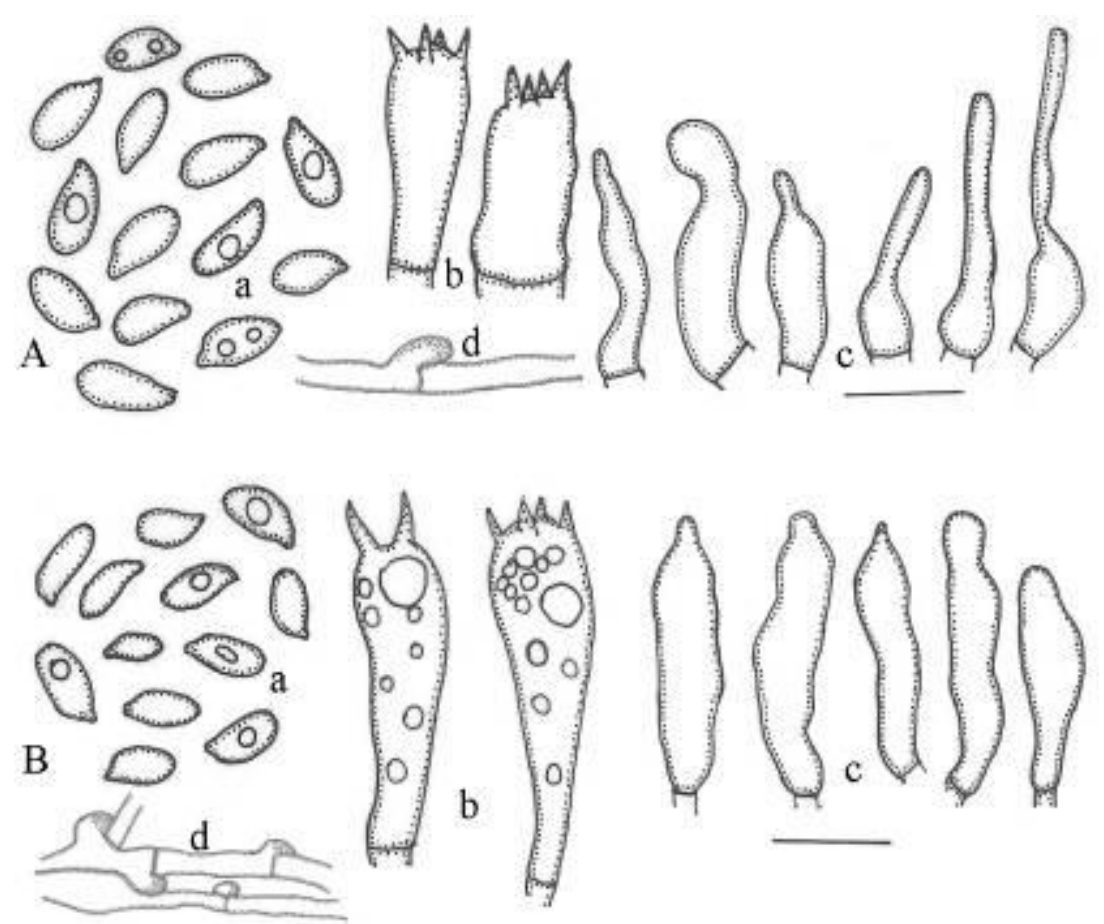

Fig. 3 - A Pterula verticillata. a. Basidiospores. b. Basidia. c. Cystidia. d. Generative hypha with clamp connection. B Pterula indica. a. Basidiospores. b. Basidia. c. Cystidia. d. Generative hyphae with clamp connections. Scale Bar $=10 \mu \mathrm{m}$.

\section{Acknowledgements}

I Sincerely thank the Department of Science and Technology (DST), Government of India, New Delhi, for providing financial support under the IRPHA Programme for setting up state-of theart National Facility for Culture Collection of Fungi (No. SP/SO/PS-55/2005) at Agharkar Research Institute, Pune, India. Sincere thanks to the Director, Agharkar Research Institute for providing laboratory facilities.

\section{References}

Corner EJH. 1950 - A monograph of Clavaria and allied genera. Oxford University Press, London, UK. 740p.

Corner EJH. 1970 - Supplement to "A monograph of Clavaria and allied genera". Beih. Nova Hedwigia 33: 1-299.

Corner EJH, Thind KS, Dev S. 1957 - The Clavariaceae of the Mussoorie Hills (India). VII. Transactions of British Mycological Society 40(4), 472-476.

Dentinger BTM, McLaughlin DJ. 2006 - Reconstructing the Clavariaceae using nuclear large subunit rDNA sequences and a new genus segregated from Clavaria. Mycologia 98(5), 746762. http://dx.doi.org/10.3852/98.5.746

Garcia-Sandoval R, Cifuentes J, Luna ED, Estrada-Torres A, Villegas M. 2005 - A phylogeny of Ramariopsis and allied taxa. Mycotaxon 94, 265-292.

Kautmanová I, Adamčík S, Lizoň P, Jančovičová S. 2012 - Revision of taxonomic concept and systematic position of some Clavariaceae species. Mycologia 104, 521-539. http://dx.doi.org/10.3852/11-121

Kirk PM, Cannon PF, Minter DW, Stalpers JA. 2008 - Dictionary of the Fungi. $10^{\text {th }}$ edn. CAB International, UK. 771p.

Kornerup A, Wanscher JH. 1978 - Methuen handbook of colour. 3rd edn. Methuen and Co., Ltd., London. 243 p.

Lloyd CG. 1919-1925 - Mycological notes. Cincinnati, Ohio, USA. 1364 p. 
Mohanan C. 2011. Macrofungi of Kerala. Kerala Forest Research Institute, Peechi, India. 597pp.

Olariaga I, Salcedo I. 2009 - Two new species of Typhula from the Iberian Peninsula: T. ochraceosclerotiata and $T$. schoeni. Mycological Progress 8, 351-357. http://dx.doi.org/10.1007/s11557-009-0608-2

Pegler DN, Young TWK. 1985 - Basidiospore structure in Ramariopsis (Clavariaceae). Transactions of British Mycological Society 84(2), 207-214.

Petersen RH. 1966 - Notes on clavarioid fungi. V. Emendation and additions to Ramariopsis. Mycologia 58, 201-207.

Petersen RH. 1967a - Type studies in the clavarioid fungi. I. Taxa described by Charles Horten Peck. Mycologia 59, 767-802.

Petersen RH. 1967b - Type studies in the Clavariaceae. Sydowia 21, 105-122.

Petersen RH. 1968a - Type studies in the clavarioid fungi. II. Nova Hedwigia 14, 407-414.

Petersen RH. 1968b - The genus Clavulinopsis in North America. Mycol Mem 2, 1-39.

Petersen RH. 1969 - Notes on clavarioid fungi. X. New species and type studies in Ramariopsis, with a key to species in North America. Mycologia 61, 549-559.

Petersen RH. 1971a - Type studies in the clavarioid fungi. IV. Specimens from herbarius Fries at Uppsala with notes on cantharelloid species. Friesia 9, 369-388.

Petersen RH. 1971b - Notes on clavarioid fungi. IX. Adendum to Clavulinopsis in North America. Persoonia 6, 219-229.

Petersen RH. 1978a - The genus Ramariopsis in southeastern Australia. Australian Journal of Botany 26, 425-431.

Petersen RH. 1978b - Notes on clavarioid fungi. XV. Reorganization of Clavaria, Clavulinopsis and Ramariopsis. Mycologia 70(3), 660-671.

Petersen RH. 1979 - Notes on clavarioid fungi. XVII. Clavulinopsis taxa in southeastern Australia. Sydowia 32, 209-223.

Petersen RH. 1984 - Type studies in clavarioid fungi. VIII. Persoonia 12, 225-237.

Petersen RH. 1988a - The clavarioid fungi of New Zealand. In: Ruscoe QW, ed. Science Information Publishing Center, DSIR Bulletin, Wellington, NewZealand. $170 \mathrm{p}$.

Petersen RH. 1988b - Notes on clavarioid fungi. XXII. Three interesting South American collections. Mycologia 80(4), 571-576. doi:10.2307/3807861

Senthilarasu G. 2013. An interesting blue species of Ramaria from Western Ghats, India. Kavaka. (accepted for publication).

Thind KS. 1961 - The Clavariaceae of India. Indian Council of Agricultural Research, New Delhi, $197 \mathrm{p}$.

Young AM, Fechner NA. 2009 - Australian coralloid fungi II-a new species of Ramaria (Gomphales) from Western Australia: Ramaria citrinocuspidata sp. nov. Australian Mycologist 28, 65-67.

Zhang P, Yang ZL, Ge ZW. 2005 - Two new species of Ramaria from southwestern China. Mycotaxon 94, 235-240. 